REFERENCES:

[1] Smolen JS, Landewe R, Breedveld FC, et al. EULAR recommendations for the management of rheumatoid arthritis with synthetic and biological disease-modifying antirheumatic drugs: 2013 update. Ann Rheum Dis 2014;73:492-509.

[2] Lenert A, Lenert P. Tapering biologics in rheumatoid arthritis: a pragmatic approach for clinical practice. Clin Rheum 2017;36:1-8.

Disclosure of Interest: None declared

DOI: 10.1136/annrheumdis-2018-eular.1858

\section{AB0475 THE INFLUENCE OF SWITCHING FROM ETANERCEPT ORIGINATOR TO ITS BIOSIMILAR ON EFFECTIVENESS AND AND THE IMPACT OF SHARED DECISION MAKING ON RETENTION AND WITHDRAWAL RATES}

W.D. Müskens ${ }^{1}$, S.A.A. Rongen-van Dartel ${ }^{1,2}$, E. Adang ${ }^{3}$, P.L. van Riel ${ }^{1,2},{ }^{1} / Q$ Healthcare, Radboud UMC, Nijmegen; ${ }^{2}$ Rheumatology, Bernhoven, Uden; ${ }^{3}$ Health Evidence, Radboud UMC, Nijmegen, Netherlands

Background: With biological patents expiring, biosimilars are becoming a realistic, less costly alternative to their originator. The data from numerous randomised clinical trials support that it is safe, effective and cost saving to switch to a biosimilar. However, real world data about efficacy, safety, and cost-effectiveness of such a switch are lacking.

Since shared decision making (SDM) is a key factor in the treatment of rheumatic diseases, a non-mandatory open label transitioning from Etanercept originator to its biosimilar was performed at the rheumatology department of Bernhoven.

Objectives: The first goal of this study was to investigate the effect of switching from Etanercept originator to its biosimilar on the effectiveness of treatment. The second aim was to analyse the effect of SDM on the 1 year retention rates and reasons for withdrawal in daily clinical practice.

Methods: All patients with rheumatoid arthritis (RA), axial spondyloarthritis ( $\mathrm{SpA}$ ) and psoriatic arthritis (PsA) that were using Etanercept originator between 0106-2016 and 23-10-2017 were informed by letter of the possibility to switch to its biosimilar. During the next outpatient visit with their rheumatologist the possibility to switch was discussed. Patients had the opportunity to ask questions regarding biosimilars and the switch to a biosimilar. If patients agreed the switch was made, with the reservation that they could switch back to the originator if they encountered difficulties with the biosimilar.

Using the registry of the rheumatology department at Bernhoven data were collected on disease activity (DA), medication use and adverse events from the moment of switch till 23-10-2017. As measure for DA the DAS28 was used for RA and PsA, the ASDAS was used for SpA. Stop reasons for biosimilars were verified using the health record system of the hospital. Reasons for change in disease activity and discontinuation of biosimilar treatment were assessed.

Results: Between 01-06-2016 and 23-10\%-2017 80\% (69 patients) of the Etanercept originator users switched to its biosimilar. These patients switched to biosimilar after a median time of 5.1 (IQR 2.8-8.3) years. By 23-10-2017, median follow-up of 307 (IQR 196-357) days, the mean DA did not significantly differ from the DA at baseline, $3.1(95 \%>\mathrm{Cl} 2.5-3.7)$ vs. $2.8(95 \%>\mathrm{Cl} 2.5-3.1)$. At end of follow-up $25 \%$ of the patients had discontinued there treatment and either switched back to originator $(18 \%)$, switched to another biological $(3 \%)$ or stopped treatment with biologicals (4\%).

Reasons for switching back to originator were adverse events (58\%), lack of effect $(17 \%)$ and "adverse event and lack of effect" (25\%). Only one serious adverse event was reported. This was a drug hypersensitivity reaction. After the patient was recovered, the originator was restarted without any difficulties.

Conclusions: An open label non-mandatory switch from Etanercept originator to its biosimilar showed that around $80 \%$ of the patients is willing to perform this switch. Switching did not affect effectiveness of treatment during one year followup. $75 \%$ of the patients were able to continue biosimilar therapy. In the 69 patients that switched only one serious adverse effect occurred.

Disclosure of Interest: None declared

DOI: 10.1136/annrheumdis-2018-eular.2408

\section{AB0476 THE EFFICACY OF IMMUNOADSORPTION WITH INFLIXIMAB THERAEPY ON THE MODULATION OF DISEASE ACTIVITY IN PATIENTS WITH SEVERE RHEUMATOID ARTHRITIS}

X. Kong, Y. Xing, C. Liu, M. Zhao. the Second Affiliated Hospital of Dalian Medical University, Dalian, China

Background: Active refractory rheumatoid arthritis (RA) is common in real-world Patients with active refractory RA usually have poor prognosis. And they respond poorly to a variety of therapies. The arrival of remission or low disease activity
(LDA) as soon as possible is an important way to improve their prognosis. We investigated the effectiveness of immunoadsorption therapy, a novel blood purification treatment, as a rapid and sustained disease-modifying therapy for active refractory RA.

Objectives: To evaluated the efficacy of additional immunoadsorption therapy (2 times) besides infliximab (IFX) ondisease remission in patients with active refractory RA.

Methods: 90 patients with serve RA were included in this study. 43 patients were treated with basic IFX $3 \mathrm{mg} / \mathrm{kg}$ +methotrexate (MTX) therapy, and otherdifferent peri 47 patients, besides of basic therapy, were previous given 2 times additional immunoadsorption therapy. IFX $3 \mathrm{mg} / \mathrm{kg}$ was infused at weeks $0,2,6,14,22$ and 30. Age, sex ration, mean disease duration and core index of disease activity in two treatment groups were collected at weeks $0,2,6$ and 30 weeks to compare the efficacy and safety of combined immunosorbent therapy in the treatment of severe RA.

Results: The baseline age, sex ration and core indexes of disease activity were comparable between the two treatment groups ( $p>0.05)$. After treatment, the core indexes of disease activity of all patients decreased significantly compared with their baseline levels $(p<0.05)$. The degree of reduction in the combined therapy group was significantly better than that in the basic treatment group $(p<0.05)$, and the proportion of ACR remission patients in the combined treatment group was higher than that in the basic treatment group at different stages after treatment. Conclusions: Additional immunoadsorption therapy can rapid relive the disease activity of serve RA patients, and the remission rate of $30 \mathrm{~W}$ was significantly higher than only IFX treatment. However, due to the limited sample size of this study, the efficacy of additional immunoadsorptionneeds further observations.

\section{REFERENCES}

[1] Firestein GS, Mclnnes IB. Immunopathogenesis of Rheumatoid Arthritis Immunity 2017 21;46(2):183-196. doi:10.1016/j.immuni.2017.02.006

[2] Alam J, Jantan I, Bukhari SNA. Rheumatoid arthritis: Recent advances on its etiology, role of cytokines and pharmacotherapy. Biomed Pharmacother 2017;92:615-633. doi:10.1016/j.biopha.2017.05.055

[3] Boissier MC, Semerano L, Challal S, et al. Rheumatoid arthritis: from autoimmunity to synovitis and joint destruction. J Autoimmun 39(3):222-228. doi:10.1016/j.jaut.2012.05.021

[4] Hu H, Luan L, Shu-Chuen L. How Quality of Life as Patient-Reported Outcome Has Been Studied for Rheumatoid Arthritis in Chinese-Speaking Population. Value in Health Regional Issues 2015;6:98-102. doi:10.1016/j. vhri.2005.03.001

[5] 5.J Firth, N Snowden, J Ledingham, et, al. The 1st National Clinical audit for Rheumatoid and Early Inflammatory Arthritis: findings and implications for nursing practice $\mathrm{Br} J$ Nurs. 2016, 25(11): 613-617. doi:10.12968/ bjon.2016.25.11.613

Acknowledgements: This study was supported by Natural foundation of Liaoning Province (2015020298), Dalian medical science research project (1712041) Disclosure of Interest: None declared

DOI: 10.1136/annrheumdis-2018-eular.3602

\section{AB0477 INHIBITION OF LARGE JOINT DESTRUCTION IN RHEUMATOID ARTHRITIS PATIENTS TREATED WITH TOCILIZUMAB}

Y. Hirano, K. Hattori, R. Yamada. Rheumatology, Toyohashi Municipal Hospital, Toyohashi, Japan

Background: Rheumatoid arthritis (RA) causes not only inflammation of small joints, such as hands and feet, but also inflammation of large joints. Destruction of large joints is correlated with impairments of physical activity in RA patients more than destruction of small joints is ${ }^{(1)}$. We experience strong inhibitory effect of inflammation in synovial joints, not only small joints but also large joints, by treatment with tocilizumab (TCZ), an antibody to IL-6 receptor in RA patients in daily clinical practice. Although inhibitory effects of small joint destruction by TCZ is well known, inhibitory effects of large joint destruction is unknown.

Objectives: This retrospective study investigated inhibitory effect of large joint destruction by TCZ treatment in RA patients.

Methods: Toyohashi RA database (TRAD) was used. TCZ was initiated in 65 RA patients in our institute. 31 cases ( 23 female and 8 male) who continued TCZ over 2 years were utilised in this study. Baseline characteristics and time course of disease activity were investigated. Delta-modified Sharp score ( $\Delta \mathrm{mTSS})$ per year was used to evaluate small joint destruction. ARASHI score ${ }^{(2)}$ was used to evaluate large joints destruction. Shoulders, elbows, hips, knees and ankles were evaluated using ARASHI score.

Results: Treatment continuation rate of TCZ was $86.3 \%$ at one year and $77.7 \%$ at two years in whole 65 cases (Kaplan-Meier methods). Baseline characteristics of 31 cases was as followed. Average age: 56 years old. Average RA duration 6.6 years. Concomitant rate of MTX: $74.2 \%$. Concomitant rate of prednisolone: 